Research Article

\title{
Analysis of the Mechanical Behavior of Bolted Beam-Column Connections with Different Structural Forms
}

\author{
Rongqian Yang ${ }^{1}$ and Xuejun Zhou $\mathbb{D}^{2}$ \\ ${ }^{1}$ School of Civil Engineering, Shandong University, Jinan 250101, China \\ ${ }^{2}$ School of Civil Engineering, Shandong Jianzhu University, Jinan 250101, China \\ Correspondence should be addressed to Xuejun Zhou; xuejunzhou@sdjzu.edu.cn
}

Received 7 November 2018; Accepted 30 December 2018; Published 3 March 2019

Academic Editor: Rosario Montuori

Copyright (C) 2019 Rongqian Yang and Xuejun Zhou. This is an open access article distributed under the Creative Commons Attribution License, which permits unrestricted use, distribution, and reproduction in any medium, provided the original work is properly cited.

\begin{abstract}
In order to study the mechanical behavior of bolted beam-column connections, the accuracy and applicability of the finite element model were firstly validated according to the published experiments on end-plate connections using ABAQUS. Then, in order to discuss the mechanical behavior of connections, three semirigid connections which are convenient for prefabricated construction, including top-and-seat angle connections with web and ear plate, extended end-plate connection, and T-stub connection, were examined using numerical simulation analysis to study and compare their capacity, hysteretic behavior, ductility, and degradation characteristics in detail. The results showed that the finite element models that were built could effectively simulate the load bearing behavior of bolted connections under both single-direction loading and cyclic loading. The three connections showed good load bearing capacity. The connectors significantly affected the energy dissipation capacity under load. The extended endplate connection demonstrated the best performance in both mechanical behavior and manufacture and installation, so it would therefore be the preferred option.
\end{abstract}

\section{Introduction}

Bolted beam-column connection joints have the advantages, such as a high degree of assemblage, quick speed of construction, energy conservation, and environmental protection, which meet the requirements of industrial building. In the Northridge earthquake in the United States in 1994 and in the Kobe earthquake in Japan in 1995, a large number of beam column welded joints displayed brittle fracture failure at the welded seams of the lower flanges [1], resulting in casualties, while the bolted joints were only lightly damaged and showed excellent seismic performance.

Relevant research [2-5] shows that the mechanical characteristics of bolted beam-column connection joints are bounded by perfectly rigid joints and ideal articulated joints, showing the characteristics of semirigid joints. The semirigid nature of the joints has a significant effect on the overall performance of the structure, and its good deformation capacity can optimize the distribution of bending moments in the steel frame, making the structure better both in stress and required quantity of steel [6-8]. There are various structural types of semirigid bolted joints, common endplate connections, steel angle connections, and T-section steel connections. The mechanical properties of these three kinds of joints at home and abroad have been studied [9-19]; however, load tests and variable analysis have basically been only carried out on one kind of joint without systematic comparison and analysis of the seismic performance of common types of semirigid structural joints, which cannot be used to guide engineering design.

Firstly, based on the existing experimental research, this paper used the finite element analysis software ABAQUS to establish an analytic finite element model of the end-plate connection, which was then compared with the experimental results to verify the accuracy and applicability of the model. Secondly, an analytic finite element model of the topseat angle connections, with web and ear plate, of extended endplate connections and T-section steel connections was 
established to contrast and analyze the performance parameters such as load-bearing capacity, hysteretic performance, ductility performance, and failure modes. The mechanical properties of semirigid joints of different structural types, structures, and proposed designs have been discussed in depth. Designers can then select the appropriate joint types according to the design requirements.

\section{Finite Element Model and Experimental Verification}

In order to verify the accuracy and applicability of the finite element model that has been established in this paper, the monotonic loading test of end-plate connections established by Guo et al. [19] was selected.

2.1. Finite Element Model. The finite element model consisted of steel beams, steel columns, end-plates, ribbed web stiffeners, and high-strength friction type bolts. An eightjoint hexahedral linear reduced integral unit, C3D8R, was selected for the simulation, and mesh refinement was manually performed on the areas of stress concentration such as bolt holes. The constitutive relationship of the steel adopted the experimental material property data from the literature. The lateral constraints, boundary conditions, and loading systems of the finite element model were all consistent with the experiment.

2.2. Experimental Verification. The experimental specimens from Guo et al. were designed at a reduced scale of $1: 2$. The sectional dimensions of each member are shown in Table 1. The sectional plastic modulus ratio of the beams and columns was 1.43 , which meets the design requirements of strong columns and weak beams of the "Code for Seismic Design of Buildings" (2016 Edition) (GB50011-2010) [20]. The specimen loading device is shown in Figure 1.

The comparison curve of the bending moment angle between the finite element analysis and the experiment is shown in Figure 2, and the comparison of the typical failure modes is shown in Figure 3. It can be seen that it is feasible to simulate the mechanical properties of semirigid joints by using the established finite element model.

\section{Comparison of the Mechanical Behavior of Semirigid Joints}

3.1. Details of the Connections. This paper selected three kinds of common semirigid joints including the top-seat angle connection with web and ear plate (J-1), the extended endplate connection (J-2), and the T-section steel connection (J-3) to establish finite element models to contrast and analyze their mechanical properties. The joint structures are shown in Figure 4. The sectional dimensions and specifications of each member of the joint are shown in Table 2.

3.2. Establishment of the Finite Element Model. The constitutive relationship of the steel used the simplified classic
TABLE 1: Specification and material of the specimen.

\begin{tabular}{lcc}
\hline Parts & Specification $(\mathrm{mm})$ & Material \\
\hline Column & $H 180 \times 180 \times 8 \times 10$ & \\
Beam & $\mathrm{H} 200 \times 150 \times 6 \times 8$ & \\
Column stiffener & $160 \times 86 \times 8$ & Q235 \\
End plate & $380 \times 150 \times 16$ & \\
Bolt & $8 \mathrm{M} 20$, level 10.9 & \\
\hline
\end{tabular}

three-straight-line model, and the parameters were determined according to the material property test of the subject, and Poisson's ratio is taken as 0.3 . The constitutive relationship of the high-strength bolts was determined according to the literature [21]. The stress-strain curves of the steel and the bolts are shown in Figure 5 .

The surfaces for building the contact relation include the contact between the bolts and the ear plates, the steel angles, the end-plates, the T-section steels, the beam flanges, the beam webs, and the column flanges, the contact between the steel angles with column flanges and beam flanges, the contact between the steel angles with the column flanges and the beam flanges, the contact between the ear plates and the beam webs, the contact between the end plates and the column flanges, the contact between the T-section steels and the column flange and the beam flange, and the contact between the bar bolts and the bolt holes. The contact type was surface-to-surface contact, and the tangential Coulomb friction was set on the contact surface with a friction coefficient of 0.35 .

According to the actual stress condition of the joint, the boundary condition of the finite element model was set as a pinned base column joint, and the top column limited the displacement in the translational direction of $X$ and $Y$ and the rotation direction around $Z$ axis. In order to prevent the lateral torsional-flexural buckling of the beam, its out-ofplane freedom (UY) was restrained at the end of the beam joints. The loads applied to the joint model included axial column forces, beam end loads, and bolt pretightening forces. The loads were applied in three stages: in the first stage, a bolt pretightening force was applied to the middle surface of the bolt using bolt load, and the bolt pretightening force was considered to be $100 \mathrm{kN}$; in the second stage, axial pressure was applied to the column top in the manner of a concentrated force, and the axial pressure ratio for the column was 0.2; in the third stage, a beam end load was applied in the manner of displacement increment control, and the loading device and the loading systems are shown in Figures 6 and 7. The overall finite element models of the joint are shown in Figure 8.

3.3. Comparison of Mechanical Behavior. The analysis results of the load bearing capacity of the joints are shown in Table 3 and Figures 9 and 10. It can be seen that the maximum bending moments of the three kinds of joints were $77.58 \mathrm{kN} \cdot \mathrm{m}, \quad 78.56 \mathrm{kN} \cdot \mathrm{m}$, and $84.42 \mathrm{kN} \cdot \mathrm{m}$, respectively, which were all greater than twice the total sectional plastic moment of the beam $(35.68 \mathrm{kN} \cdot \mathrm{m})$ and met the requirements for "strong joint and weak member." The plastic 


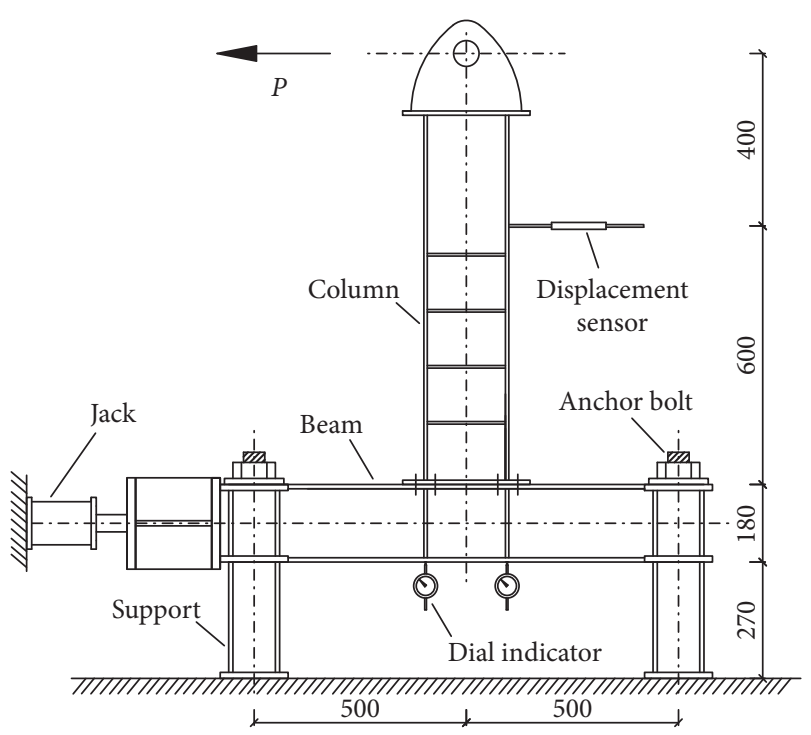

(a)

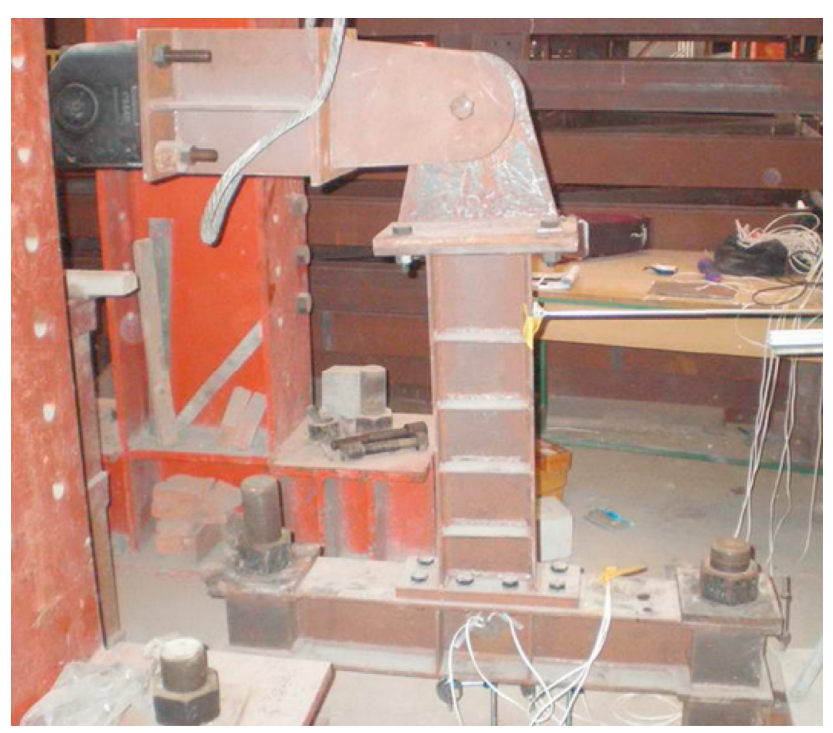

(b)

Figure 1: Test setup. (a) Design setup. (b) Practical setup.

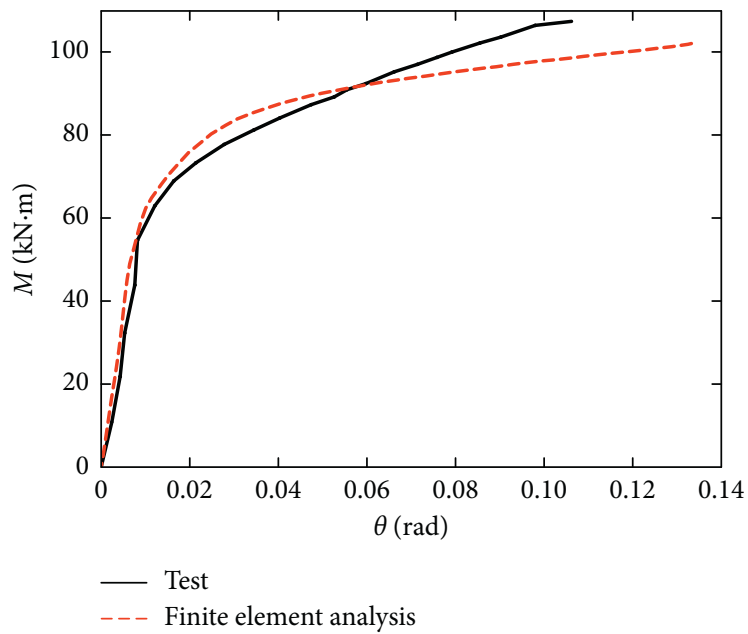

Figure 2: Comparison of the $M-\theta$ curve.

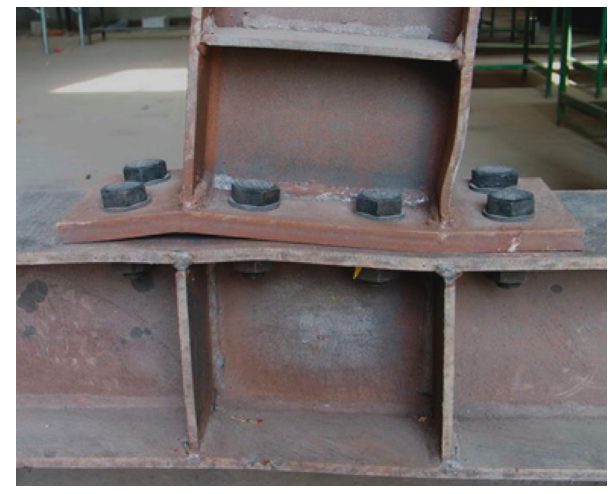

(a)

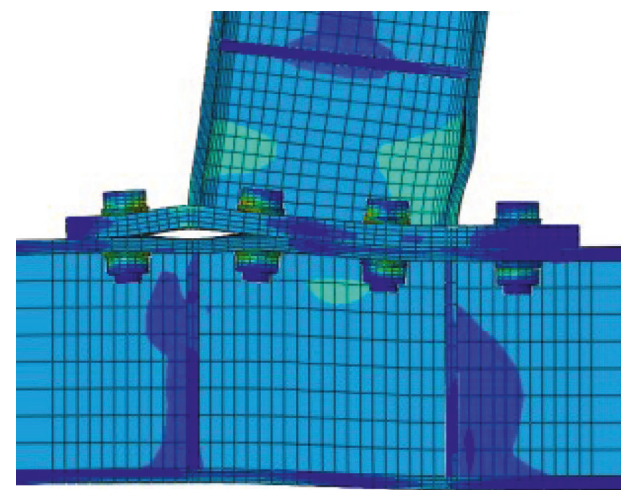

(b)

Figure 3: Comparison of the failure mode. (a) Experiment. (b) FEM. 


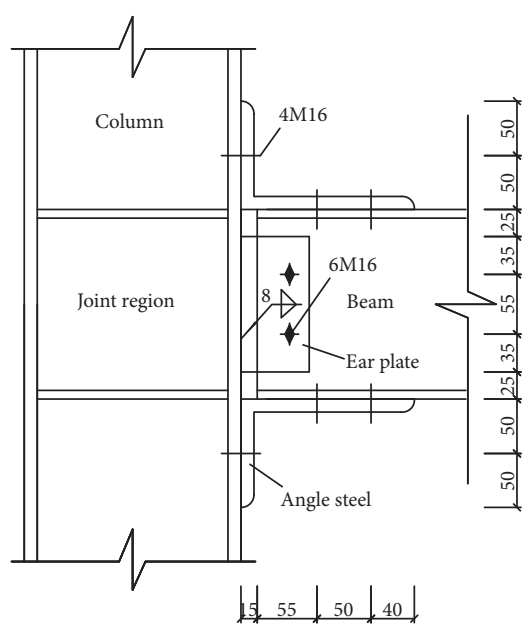

(a)
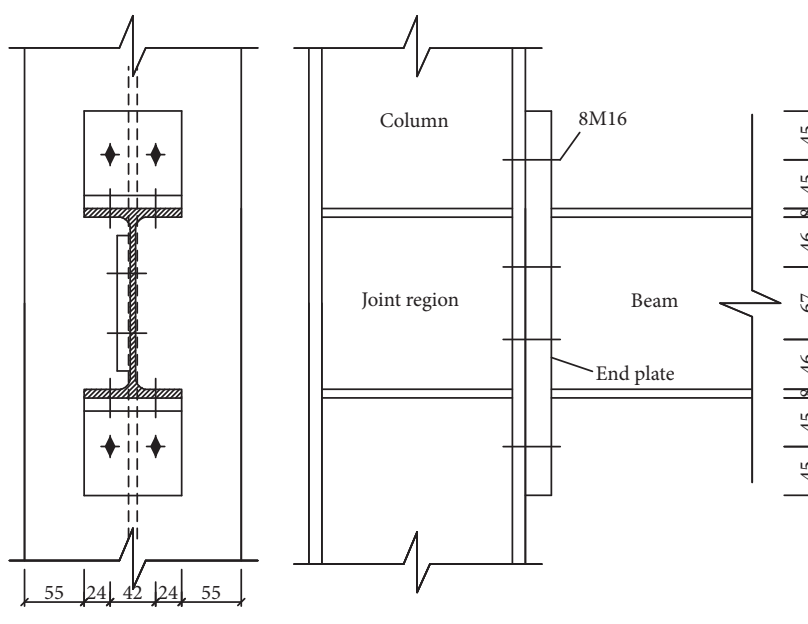

(b)

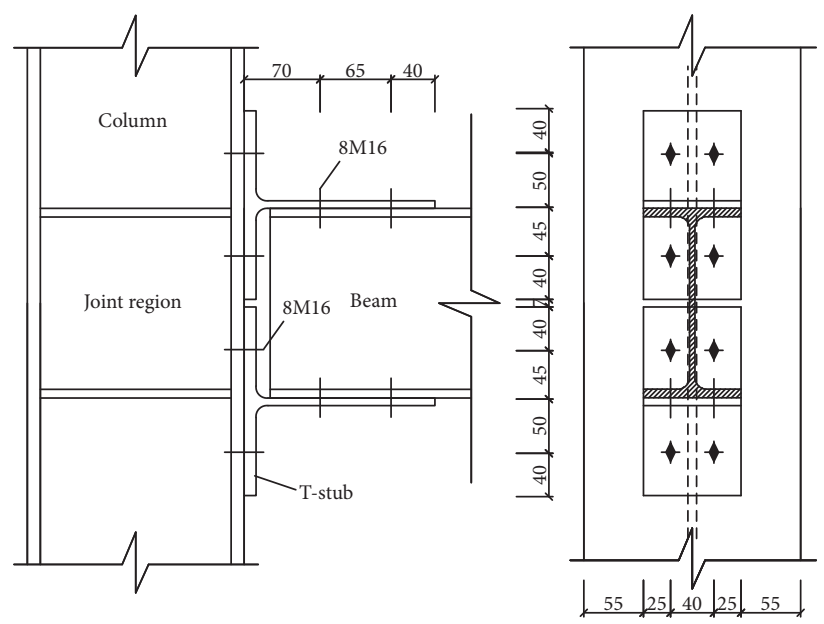

(c)

Figure 4: Joint details. (a) J-1. (b) J-2. (c) J-3.

TABLe 2: Specification and material of the specimens.

\begin{tabular}{lcc}
\hline Parts & Specification $/ \mathrm{mm}$ & Material \\
\hline Column & HW $200 \times 200 \times 8 \times 12$ & \\
Beam & HN $175 \times 90 \times 5 \times 8$ & \\
Column stiffener & $176 \times 96 \times 8$ & \\
Steel angle & L $140 \times 90 \times 12$ & \\
Ear plate & $65 \times 125 \times 12$ & Q235 \\
End plate & $355 \times 145 \times 24$ & \\
T-stub & T175 $\times 175 \times 7 \times 11$ & \\
Bolt & M16, 10.9 grade & \\
\hline
\end{tabular}

hinge would not generate on the joints but the beam-end. The load bearing capacity and elastic rigidity of J-3 were the highest, and J-3's load bearing capacity was $7.5 \%$ and $8.8 \%$ higher and J-3's stiffness was $1.7 \%$ and $21.1 \%$ higher than that of J-1 and J-2, respectively. The next was the load bearing capacity and rigidity of $\mathrm{J}-2$, which was $1.3 \%$ and $19.0 \%$ higher than that of J-1, respectively. The load bearing capacity of J-1 was the worst.

3.4. Comparison of Hysteretic Behavior. It can be seen from Figure 11 that the hysteresis curves of the three kinds of

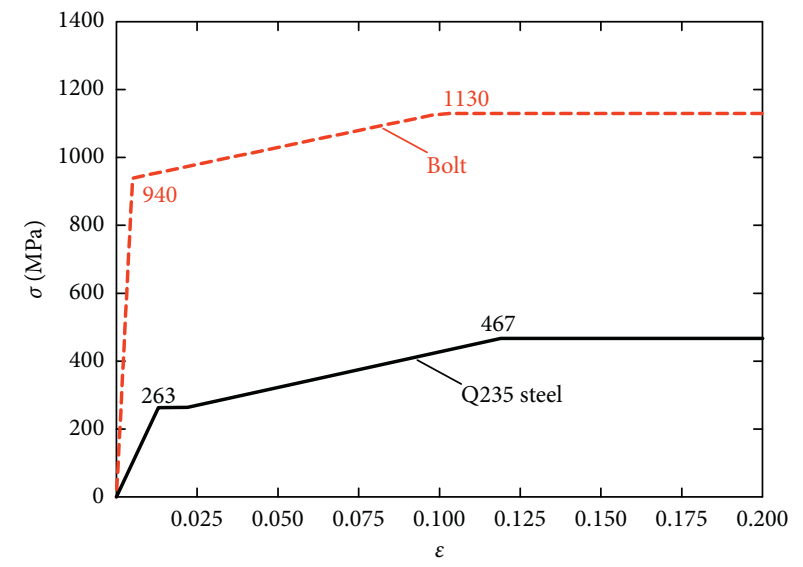

FIGURE 5: Stress-strain curve of Q235 steel and the high-strength bolts.

joints were all full in shape, but due to the large plastic deformation of the connecting pieces, the hysteresis curves of the J-1 and J-3 joints had a certain reduction of pinch which showed that the hysteretic performance was not as 


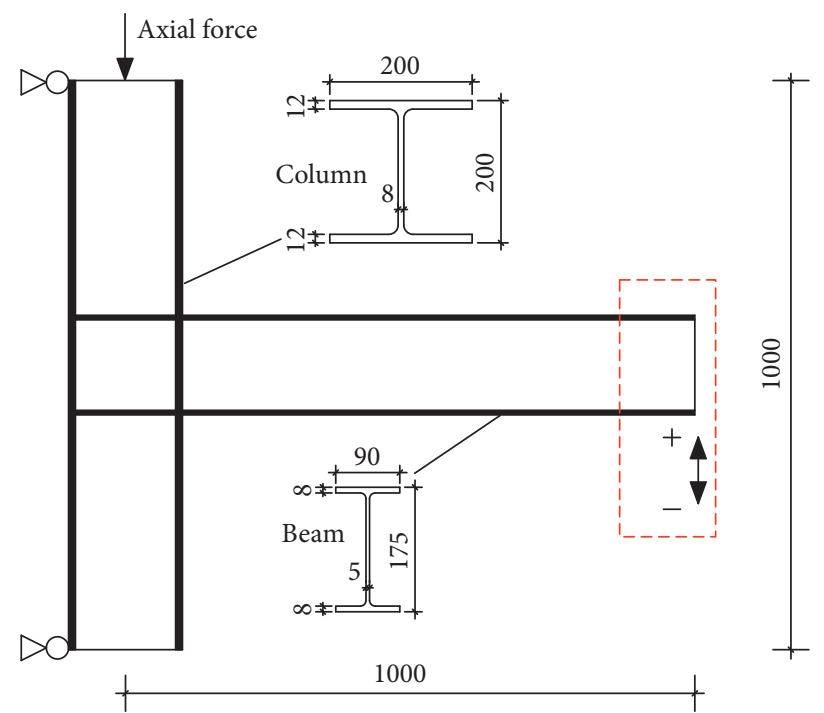

Figure 6: Loading device.

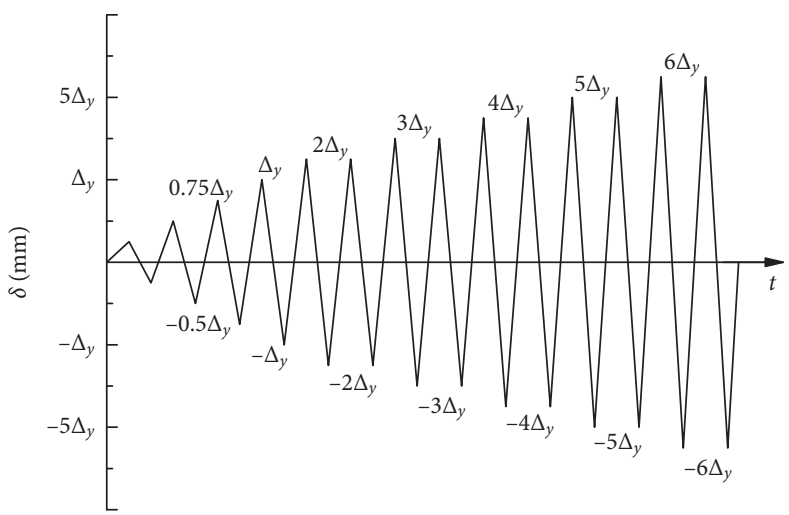

FIGURE 7: Loading scheme.

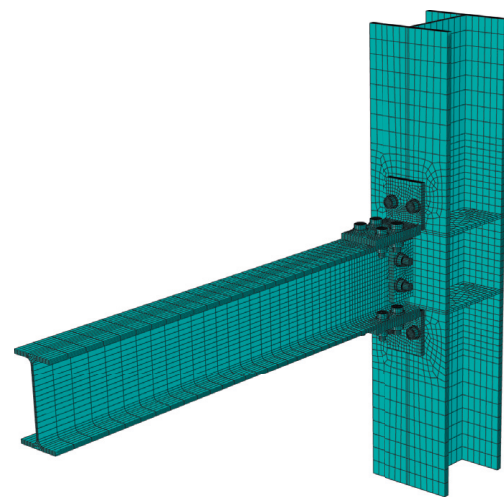

(a)

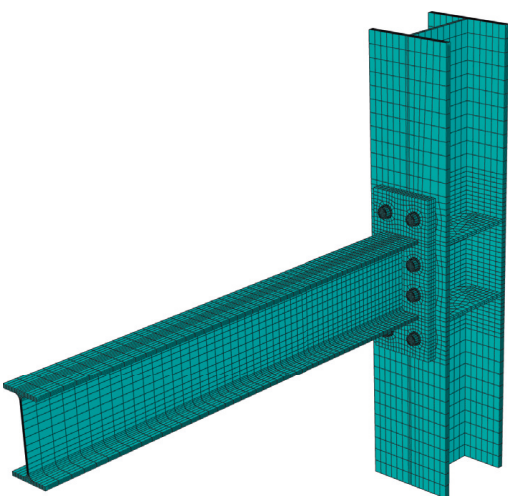

(b)

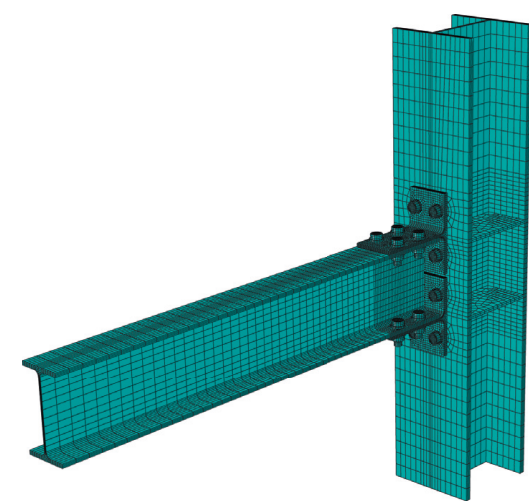

(c)

Figure 8: Finite element models of the joints. (a) J-1. (b) J-2. (c) J-3.

good as the J-2 joint. The hysteresis curves of the joint model are all lower than that of the monotonic loading curves. This is because under cyclic loading and due to the Bauschinger effect, the plastic deformation of the joints continuously accumulates, and the local buckling phenomenon becomes more obvious, resulting in the degradation of the strength and rigidity.
It can be seen from the skeleton curve in Figure 12 that the skeleton curves of the J-1 and J-2 joints were roughly the same as the monotonic loading curve. In the initial hysteresis, the skeleton curve and the monotonic loading curve of J-3 joint basically coincided. With the increase of the load, the skeleton curve was no longer smooth and although the load bearing capacity kept rising, it was not stable. It has 
TABLE 3: Comparison of load bearing behavior.

\begin{tabular}{lccc}
\hline Joint number & Yield load $(\mathrm{kN})$ & Peak load $(\mathrm{kN})$ & $\begin{array}{c}\text { Elastic stiffness } \\
(\mathrm{kN} \cdot \mathrm{m})\end{array}$ \\
\hline J-1 & 46.75 & 103.44 & 10149.55 \\
$\mathrm{~J}-2$ & 55.61 & 104.75 & 12075.66 \\
J-3 & 56.57 & 112.57 & 12286.12 \\
\hline
\end{tabular}

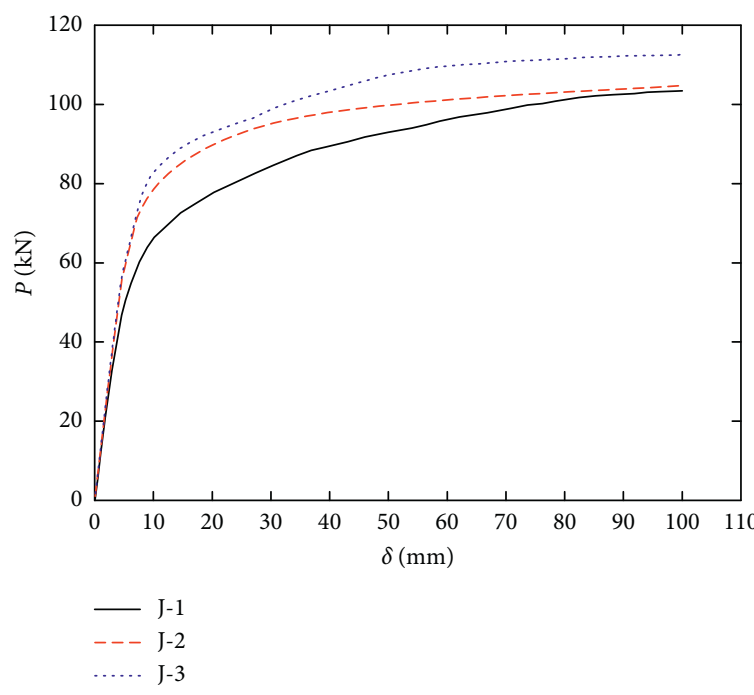

Figure 9: Comparison of the monotonic curves.

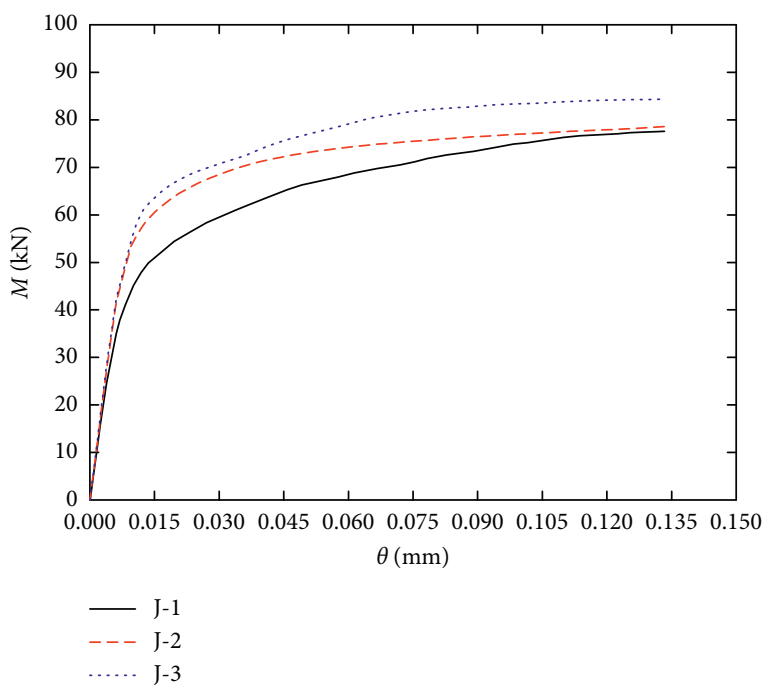

FIgURE 10: Comparison of the moment-rotation curves.

been speculated that the connecting pieces at the area of the beam flanges (top-and-seat steel angles and T-section steels) have a larger plastic deformation during the late stages of loading.

3.5. Comparison of the Energy Dissipation Capacity. The energy dissipation capacity of a joint can be measured by the energy dissipation coefficient. The larger the value, the stronger the energy dissipation capacity. The energy dissipation coefficient is calculated according to the following formula:

$$
E=\frac{S_{(\mathrm{ABC}+\mathrm{CDA})}}{S_{(\mathrm{OBE}+\mathrm{ODF})}},
$$

where $S_{(\mathrm{ABC}+\mathrm{CDA})}$ represents the area enclosed by the hysteresis loop and $S_{(\mathrm{OBE}+\mathrm{ODF})}$ represents the area enclosed by the corresponding triangle, as shown in Figure 13.

Figure 14 shows that after entering the yield phase, the energy dissipation coefficient of the J-2 joints was greater than 2.3, and the energy dissipation capacity was excellent. However, the energy dissipation coefficient of the J-3 joint was $1.0 \sim 1.5$, the energy dissipation coefficient of the J-1 joint was about 1.0, and their energy dissipation performance was not good. The reason for this is that the screw shear force borne around the bolt holes of the top-and-seat steel angles and T-section steel webs produced plastic deformation and was gradually accumulated, and the deformation of the bolt holes was obvious, and the energy dissipation capacity of the connection under cyclic loading was not fully realized. The value of the energy dissipation coefficient was consistent with the full degree of the hysteresis loop of the joint.

3.6. Comparison of Degradation Characteristics. The plastic deformation generated by the joint under cyclic loading was continuously accumulated, which might cause the degradation of the load-bearing capacity and rigidity. The loadbearing capacity degradation can be measured by the reduced loading coefficient $\lambda_{i}$ (formula (2)), and the rigidity degradation can be calculated by the secant stiffness $K_{i}$ under the same cycle:

$$
\begin{aligned}
\lambda_{j} & =\frac{F_{j}^{i+1}}{F_{j}^{i}}, \\
K_{i} & =\frac{\left|+F_{i}\right|+\left|-F_{i}\right|}{\left|+X_{i}\right|+\left|-X_{i}\right|} .
\end{aligned}
$$

In the formula, when $j$ is the displacement ductility factor, $F_{j}^{i}$ is the peak load of the $i$ th cycle and when $j$ is the displacement ductility factor, $F_{j}^{i+1}$ is the peak load of the $i+$ 1th cycle; $\pm F_{i}$ is the peak load of the cycle; and $\pm X_{i}$ is the displacement of the peak of the cycle.

Figure 15 shows the variation trend of the decreasing load coefficient of the joint with load. It can be seen that the decreasing load-bearing capacity coefficient of the joint was greater than 0.93 , indicating that the load-bearing capacity degradation of each cycle of the same loading stage was small and its stability was good. Comparing the three kinds of joints, the decreasing load coefficients of the J-2 and J-3 joints were greater than that of J-1 joint without drastic change, indicating that the stability of the load-bearing capacity was better than that of the J-1 joint. However, because the plastic deformation of J-1 joint occurs in the top and bottom steel angle area where the web bolts are kept continuously and gradually accumulates, resulting in relatively unstable bearing capacity, the producing plastic deformation at the area of the top-and-seat steel angle and the web bolt resulted in a relatively less stable load bearing capacity of J-1 joint. After entering the yield phase, the 


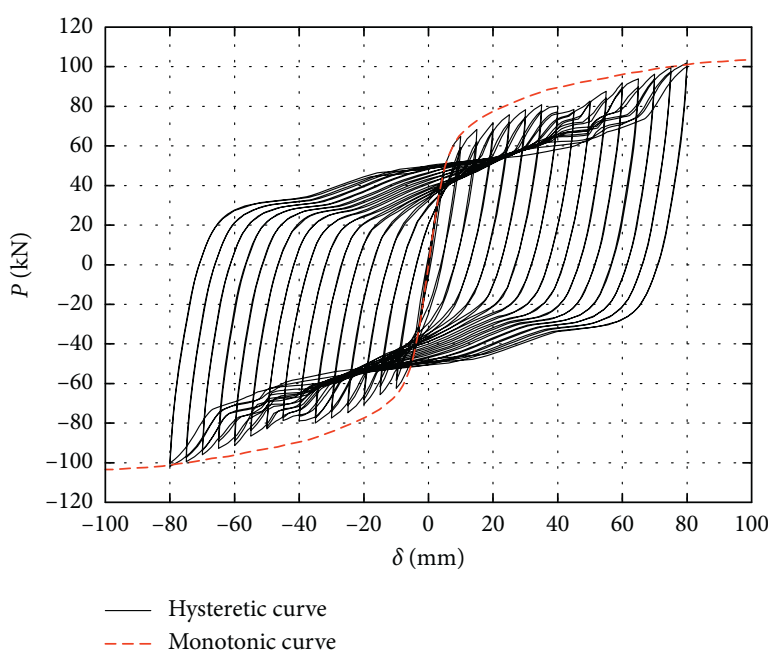

(a)

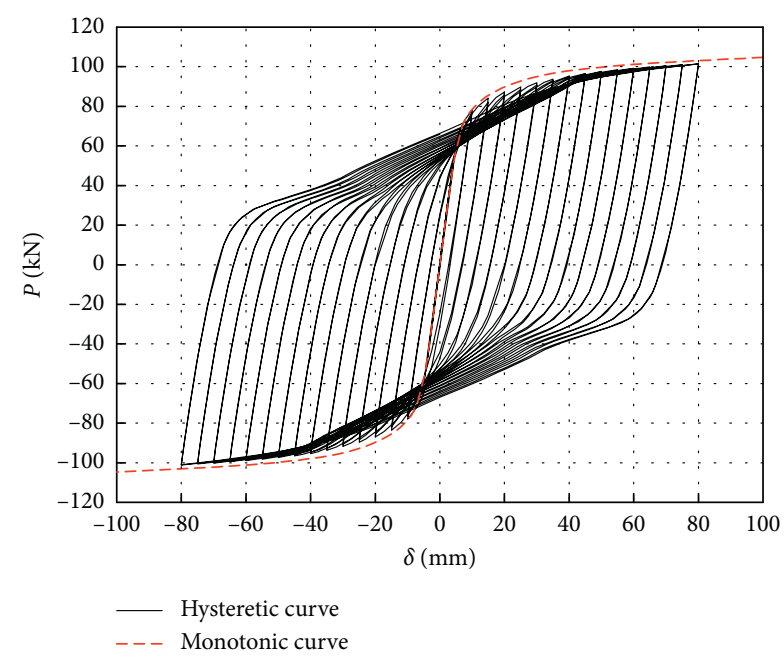

(b)

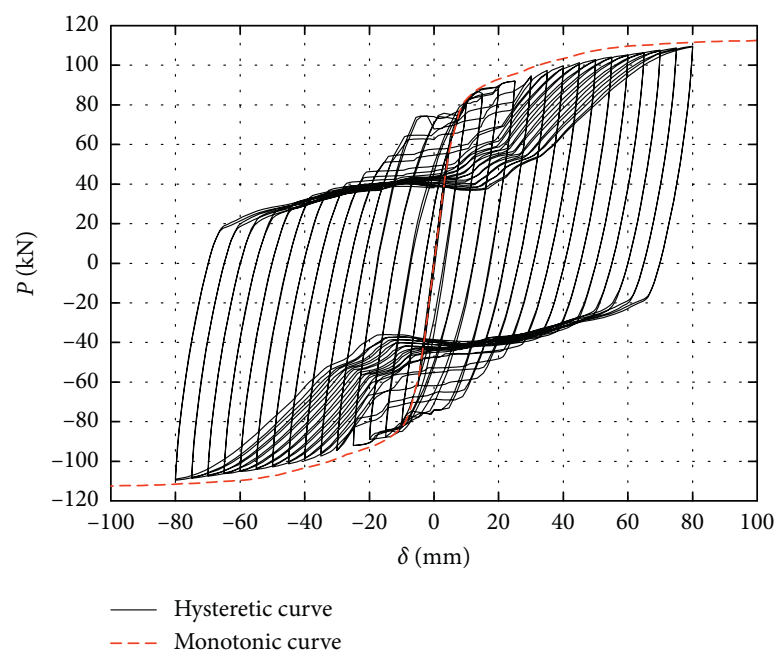

(c)

Figure 11: Hysteretic curves of the joints. (a) J-1. (b) J-2. (c) J-3.

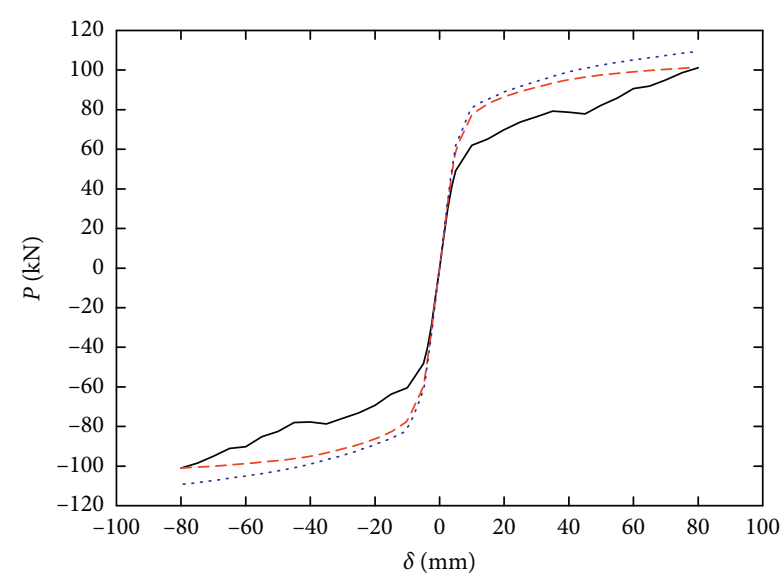

$-\mathrm{J}-1$
$---\mathrm{J}-2$

….. J-3

FIgURE 12: Skeleton curves of the joints.

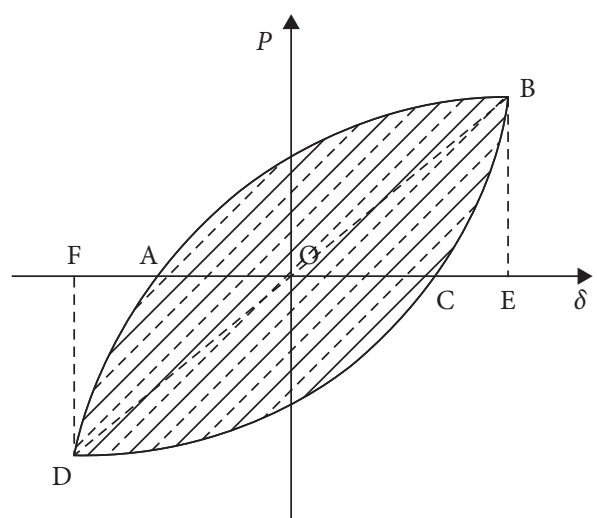

Figure 13: Calculation of dissipative coefficient.

stability of the load-bearing capacity of the J-2 joint was better than that of $\mathrm{J}-3$.

Table 4 and Figure 16 show that the initial rigidity of the $\mathrm{J}-3$ joint was the largest, followed by $\mathrm{J}-2$ and then $\mathrm{J}-1$, which 


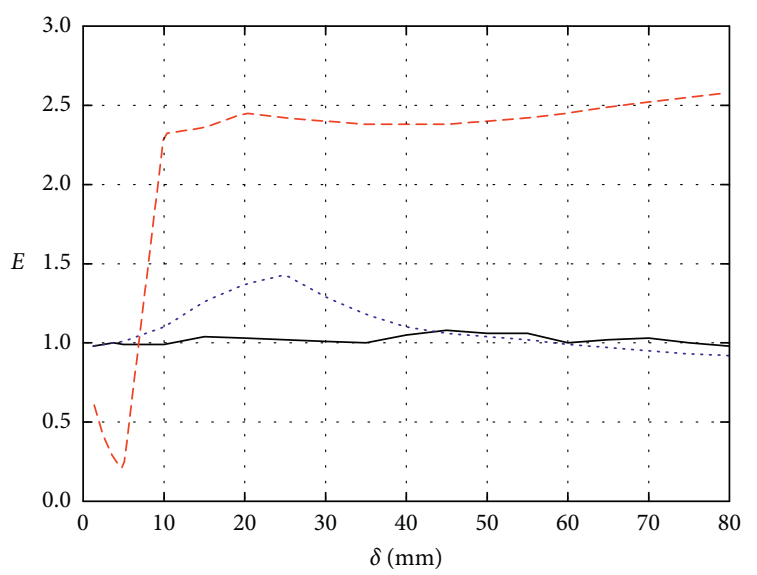

$-\mathrm{J}-1$
$---\mathrm{J}-2$
$\cdots-\mathrm{J}-3$

Figure 14: Comparison of the dissipative coefficient.

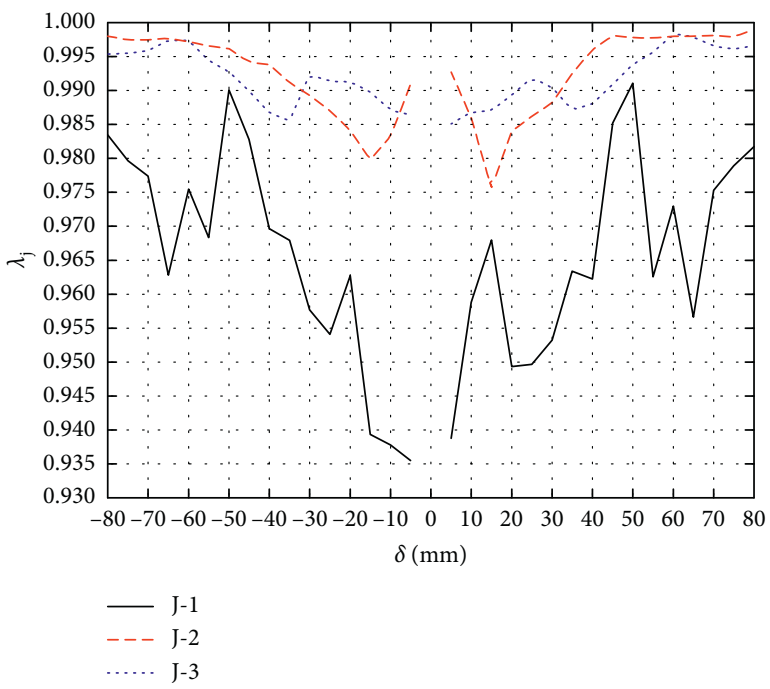

FIGURE 15: Comparison of the capacity degeneration coefficient.

was consistent with the monotonic loading analysis results. The rigidity of the three types of joints degenerated rapidly in the initial stage of loading, and the final rigidity degradation degrees were all at $90 \%$ with the final ratio of rigidity (ratio of the secant stiffness of each cycle to the secant stiffness of the first cycle) tending to be 0.1 . The rigidity degradation curves of the J-2 and J-3 joints basically coincided, while under the same loading level, the ratio of the rigidity of J-1 was lower than that of the J-2 and J-3 joints, indicating that the rigidity of J-1 degraded faster under stress which was not conducive to seismic resistance.

3.7. Comparison of Failure Mode. Figure 17 shows that the stress level of the J-2 joint was the lowest, followed by the J-3 joint, while the J-1 joint was the highest. The failure of the J-1 joint was mainly displayed as the deformation of the area of the top-and-seat steel angle and the bolt holes of the beam web (Figure 18(a)). The failure of the J-3 nodes was mainly
TABLE 4: Stiffness of the joints.

\begin{tabular}{lccc}
\hline Loading grade & $\mathrm{J}-1$ & $\mathrm{~J}-2$ & $\mathrm{~J}-3$ \\
\hline $0.25 \Delta_{y}$ & 12.13 & 13.01 & 13.54 \\
$0.5 \Delta_{y}$ & 11.72 & 12.86 & 13.44 \\
$0.75 \Delta_{y}$ & 10.92 & 12.55 & 13.11 \\
$\Delta_{y}$ & 9.75 & 11.96 & 12.40 \\
$2 \Delta_{y}$ & 6.13 & 7.75 & 8.19 \\
$3 \Delta_{\mathrm{y}}$ & 4.30 & 5.53 & 5.66 \\
$4 \Delta_{y}$ & 3.48 & 4.32 & 4.45 \\
$5 \Delta_{y}$ & 2.94 & 3.56 & 3.67 \\
$6 \Delta_{y}$ & 2.54 & 3.04 & 3.15 \\
$7 \Delta_{y}$ & 2.26 & 2.67 & 2.76 \\
$8 \Delta_{y}$ & 1.96 & 2.38 & 2.48 \\
$9 \Delta_{y}$ & 1.73 & 2.14 & 2.24 \\
$10 \Delta_{y}$ & 1.65 & 1.95 & 2.05 \\
$11 \Delta_{y}$ & 1.55 & 1.79 & 1.89 \\
$12 \Delta_{y}$ & 1.51 & 1.65 & 1.75 \\
$13 \Delta_{y}$ & 1.41 & 1.53 & 1.63 \\
$14 \Delta_{y}$ & 1.36 & 1.43 & 1.53 \\
$15 \Delta_{y}$ & 1.31 & 1.34 & 1.45 \\
$16 \Delta_{y}$ & 1.26 & 1.27 & 1.37 \\
\hline
\end{tabular}

concentrated on the area of the bolt holes of the T-section steel webs under the shearing force of the screws, and a large amount of plastic deformation was accumulated (Figure 18(b)). For J-2, due to the thicker end-plate, there was almost no plastic deformation on the connection between the end-plates and the bolt, and the failure of the joint was mainly displayed in the bending deformation at the ends of the beams. The ductility and bearing capacity of the joints were increased with good seismic performance due to the outward hinged plastic movement.

3.8. Comparison of Joint Performance. In conclusion, a comprehensive contrastive analysis of the three types of semirigid joints is shown in Table 5.

\section{Conclusions}

Based on the analysis of the three kinds of beam-column bolted connections, the following conclusions can be drawn for the connections:

(1) The finite element models that were built could effectively simulate the load-bearing behavior of bolted connections under single-direction loading and $\mathrm{cy}-$ clic loading. The rationality of the element type and constitutive relation was verified to be correct.

(2) The three connections all showed stable and good load-bearing capacity hysteretic behavior and energy dissipation capacity, which could make the plastic hinge generate on the beam-end instead of the connections. Therefore, the ductility of steel frame could be promoted effectively.

(3) The extended end-plate connection had the best energy dissipation capacity because no obvious deformation generated on the end-plate. The connectors, such as the steel angle and T-stub, had large 


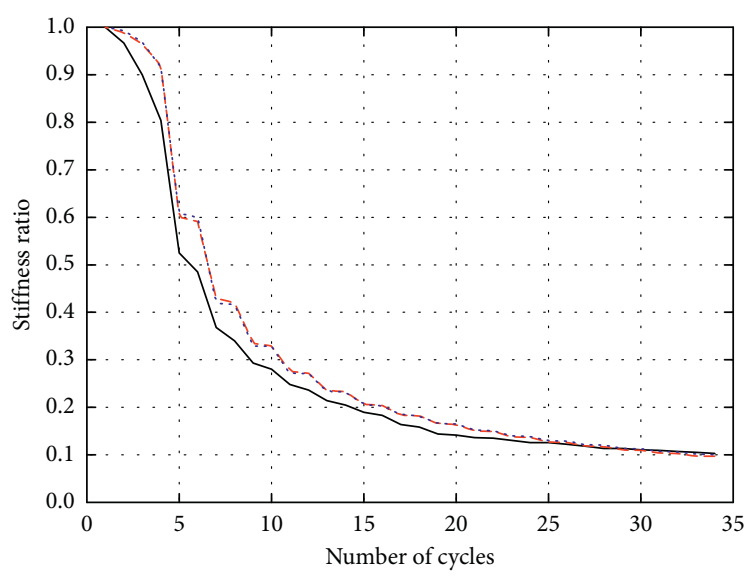

$-\mathrm{J}-1$
$--\mathrm{J}-2$

…. J-3

Figure 16: Comparison of stiffness degeneration.

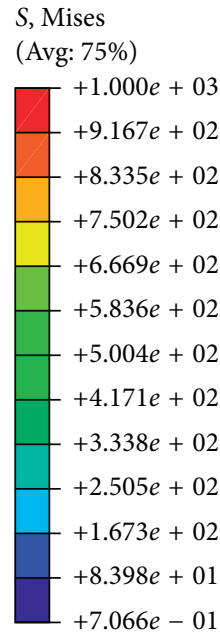

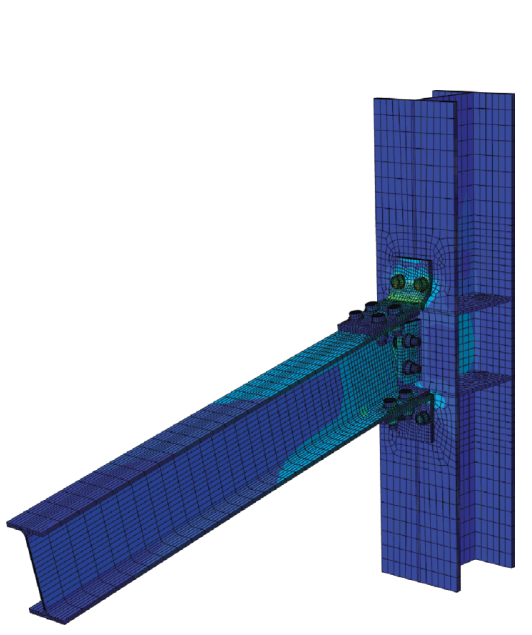

(a)
$S$, Mises

(Avg: 75\%)

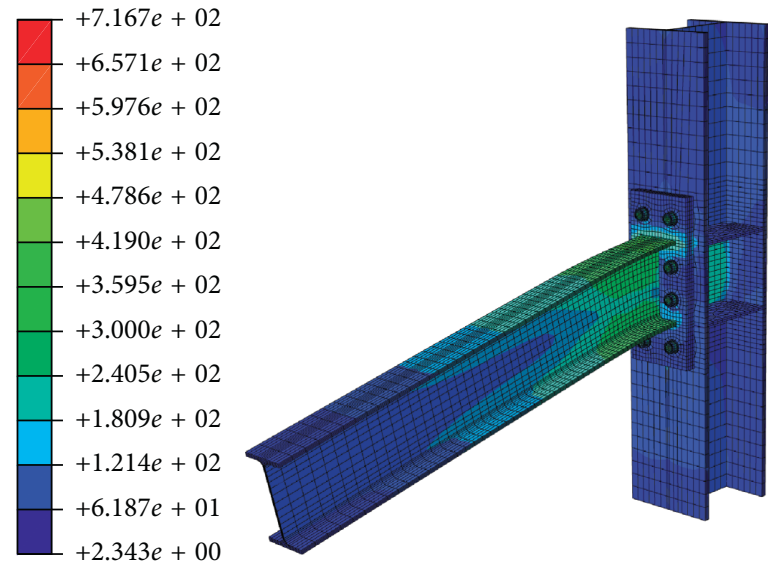

(b)

$S$, Mises

(Avg: 75\%)

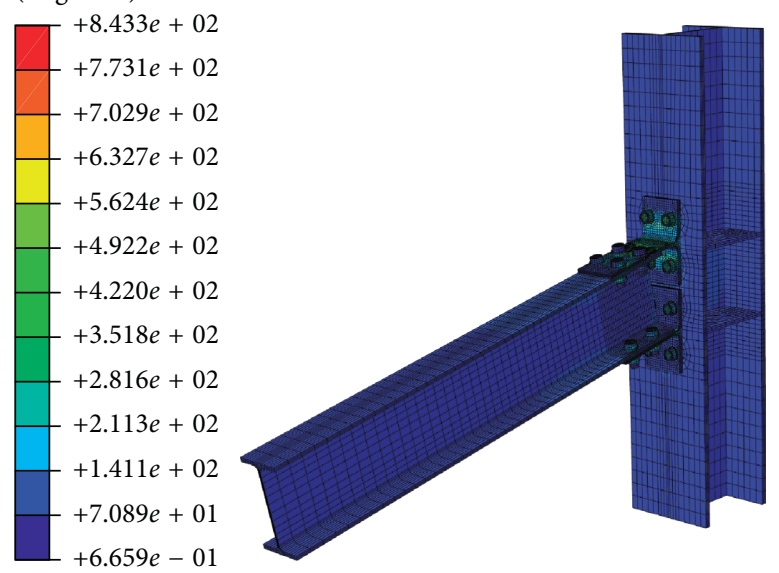

(c)

FIgURE 17: Stress nephogram of the joints. (a) J-1. (b) J-2. (c) J-3. 


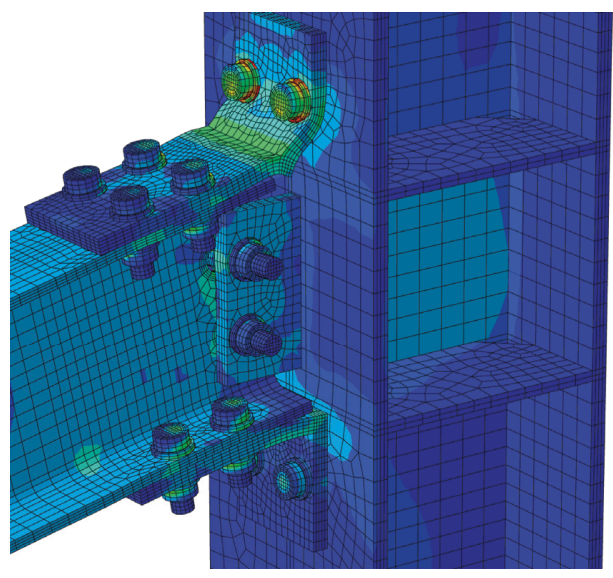

(a)

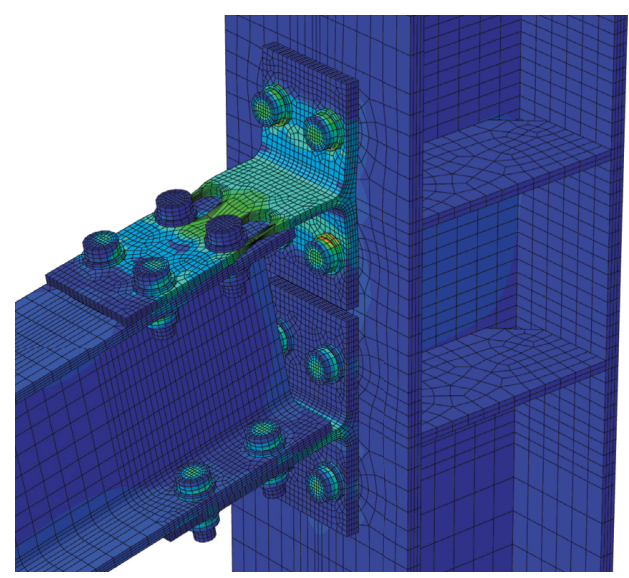

(b)

Figure 18: Local deformation. (a) J-1. (b) J-2.

TABle 5: Comparison of joint performance.

\begin{tabular}{lcccccc}
\hline Number & Bearing behavior & Hysteretic behavior & Energy dissipation & Bearing degradation & Stiffness degradation & Failure mode \\
\hline J-1 & $\times$ & $\times$ & $\times$ & $\times$ & $\times$ \\
J-2 & $O$ & $\sqrt{ }$ & $\sqrt{ }$ & $\sqrt{ }$ & $\times$ \\
J-3 & $\sqrt{ }$ & $O$ & $\times$ & $O$ & $\sqrt{ }$ & $\times$ \\
\hline
\end{tabular}

Note. $\sqrt{ }$, good; $\mathrm{O}$, medium; $\times$, poor.

deformation and significantly affected the energy dissipation capacity and the failure mode.

(4) Comprehensive consideration: the extended endplate connection showed good mechanical performance in manufacture and installation, and it should be used for preference. The T-stub connection took second place. The top-and-seat angle connection with the web and ear plate requires the highest installation precision, and its manufacture is tedious which means it should be avoided in building construction.

\section{Data Availability}

No data were used to support this study.

\section{Conflicts of Interest}

The authors declare that there are no conflicts of interest regarding the publication of this article.

\section{References}

[1] F. Hu, G. Shi, Y. Shi et al., "Finite element analysis on seismic performance of specifically pre-fabricated beam-column connections," Engineering Mechanics, vol. 32, no. 6, pp. 6975, 2015.

[2] W. F. Chen, Steel Beam-to-Column Building Connections, Elsevier Science Publishing Co., Inc., New York, NY, USA, 1988.

[3] W. F. Chen and F. M. Lui, Stability Design of Steel Frames, CRC Press, Boca Raton, FL, USA, 1991.
[4] J. Y. R. Liew, C. H. Yu, Y. H. Ng, and N. E. Shanmugam, "Testing of semi-rigid unbraced frames for calibration of second-order inelastic analysis," Journal of Constructional Steel Research, vol. 41, no. 2-3, pp. 159-195, 1997.

[5] D. A. Nethercot, T. Q. Li, and B. Ahmed, "Unified classification system for beam-to-column connections," Journal of Constructional Steel Research, vol. 45, no. 1, pp. 39-65, 1998.

[6] J. M. Cabrero and E. Bayo, "Development of practical design methods for steel structures with semi-rigid connections," Engineering Structures, vol. 27, no. 8, pp. 1125-1137, 2005.

[7] J. Hao and W. Li, "Finite element analysis for the top-and-seat angle minor axis connection of semi-rigid steel beam-column joints," China Civil Engineering Journal, vol. 40, no. 9, pp. 36-42, 2007.

[8] G. Li, W. Shi, and J. Wang, Design of Steel Frames with SemiRigid Connections, China Architecture \& Building Press, Beijing, China, 2009.

[9] A. R. Kukreti, M. Ghassemieh, and T. M. Murray, "Behavior and design of large-capacity moment end plates," Journal of Structural Engineering, vol. 116, no. 3, pp. 809-828, 1990.

[10] B. T. Adey, G. Y. Grondin, and J. J. Cheng, "Cyclic loading of end plate moment connections," Canadian Journal of Civil Engineering, vol. 27, no. 4, pp. 68-701, 2000.

[11] J. Shen and A. Astaneh-Asl, "Hysteretic behavior of boltedangle connections," Journal of Constructional Steel Research, vol. 51, no. 3, pp. 201-218, 1991.

[12] V. Piluso and G. Rizzano, "Experimental analysis and modelling of bolted T-stubs under cyclic loads," Journal of Constructional Steel Research, vol. 64, no. 6, pp. 655-669, 2008.

[13] G. Shi, Y. Shi, Y. Wang, and M. A. Bradford, "Numerical simulation of steel pretensioned bolted end-plate connections of different types and details," Engineering Structures, vol. 30, no. 10, pp. 2677-2686, 2008. 
[14] B. M. Broderick and A. W. Thomson, "The response of flush end-plate joints under earthquake loading," Journal of Constructional Steel Research, vol. 58, no. 9, pp. 1161-1175, 2002.

[15] M. Wang, Y. Shi, Y. Wang, and G. Shi, "Numerical study on seismic behaviors of steel frame end-plate connections," Journal of Constructional Steel Research, vol. 90, pp. 140-152, 2013.

[16] M. Gerami, H. Saberi, V. Saberi, and A. Saedi Daryan, "Cyclic behavior of bolted connections with different arrangement of bolts," Journal of Constructional Steel Research, vol. 67, no. 4, pp. 690-705, 2011.

[17] O. S. Bursi and J. P. Jaspart, "Benchmarks for finite element modelling of bolted steel connections," Journal of Constructional Steel Research, vol. 43, no. 1-3, pp. 17-42, 1997.

[18] Z. Li, X. Li, X. Zheng, and K. Zhang, "Experimental study and numercial investigation on hysteretic behavior of T-stub semi-rigid beam-to-column connections," Journal of Building Structures, vol. 35, no. 7, pp. 61-68, 2014.

[19] B. Guo, L. Wang, Y. Wang et al., "Experimental study on rotational stiffness of steel frame beam-column connections," Journal of Building Structures, vol. 32, no. 10, pp. 82-89, 2011.

[20] GB50011-2010, Code for Seismic Design of Buildings, China Architecture \& Building Press, Beijing, China, 2016.

[21] T. Wang, Study on Moment-Rotation Relationship of EndPlate Connections and Seismic Behavior of Semi-Rigid Steel Frames, South China University of Technology, Guangzhou, China, 2013. 


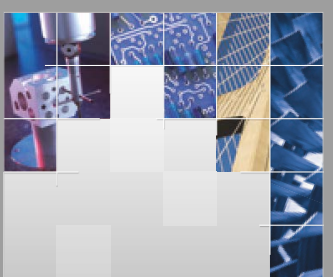

\section{Enfincering}
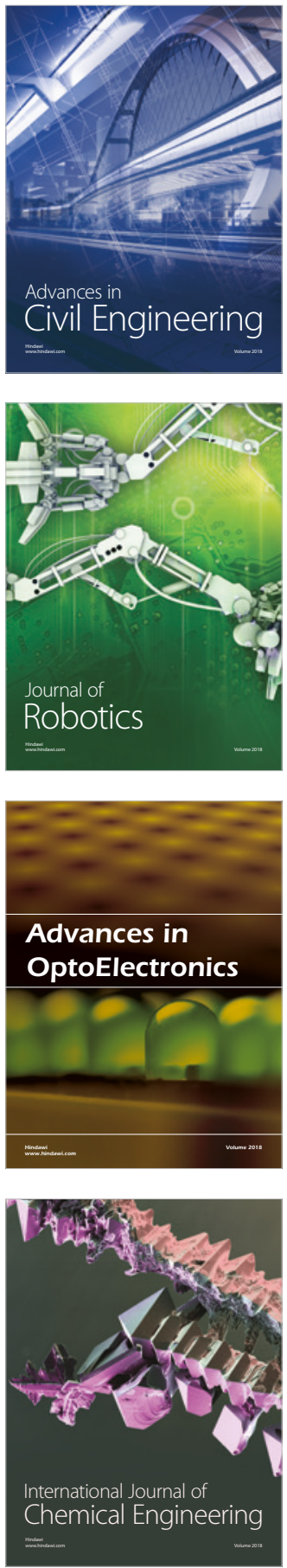

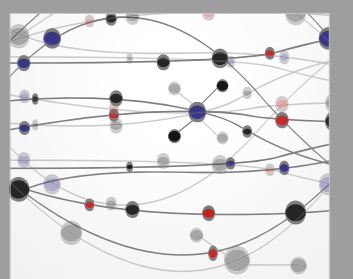

\section{Rotating \\ Machinery}

The Scientific World Journal

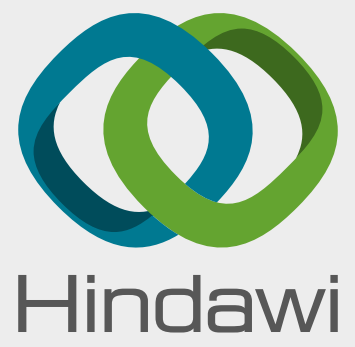

Submit your manuscripts at

www.hindawi.com
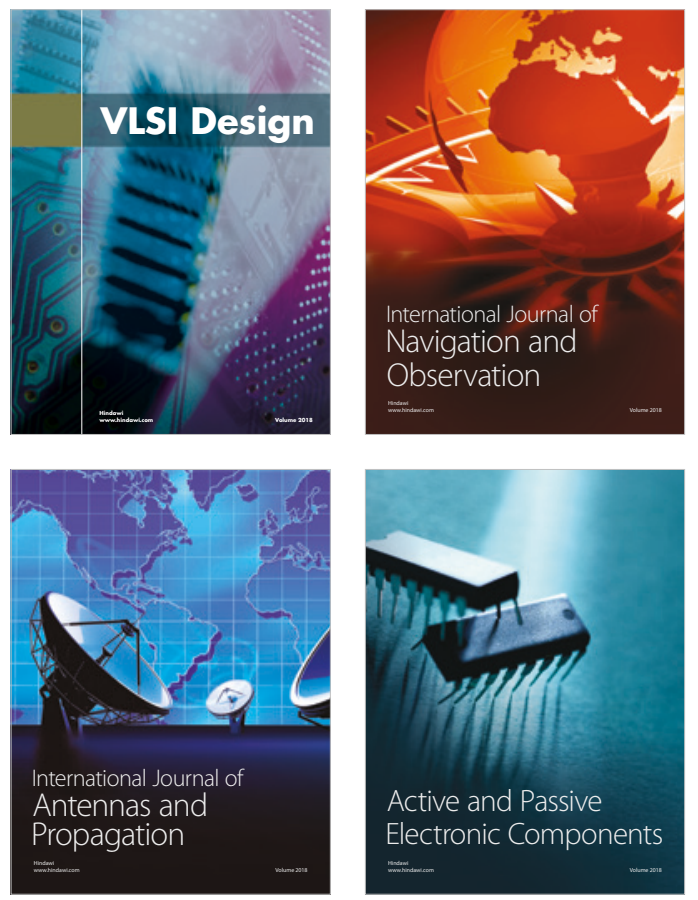
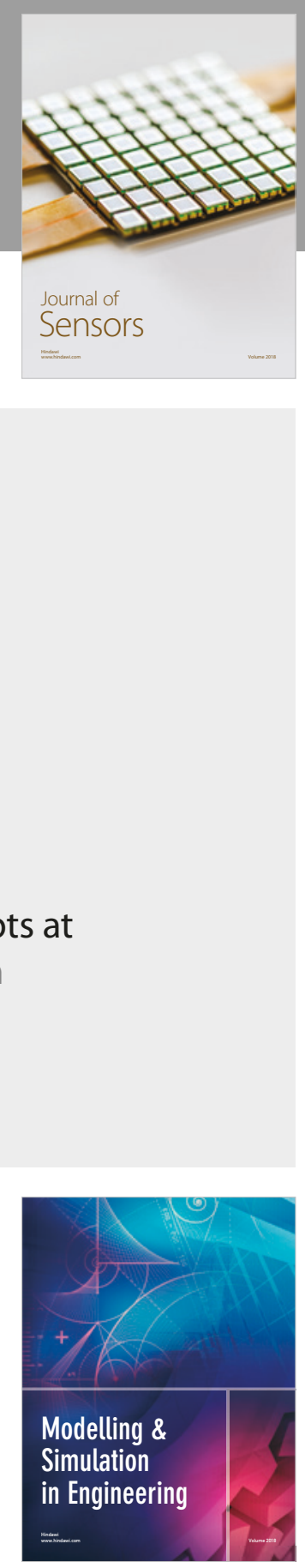

\section{Advances \\ Multimedia}
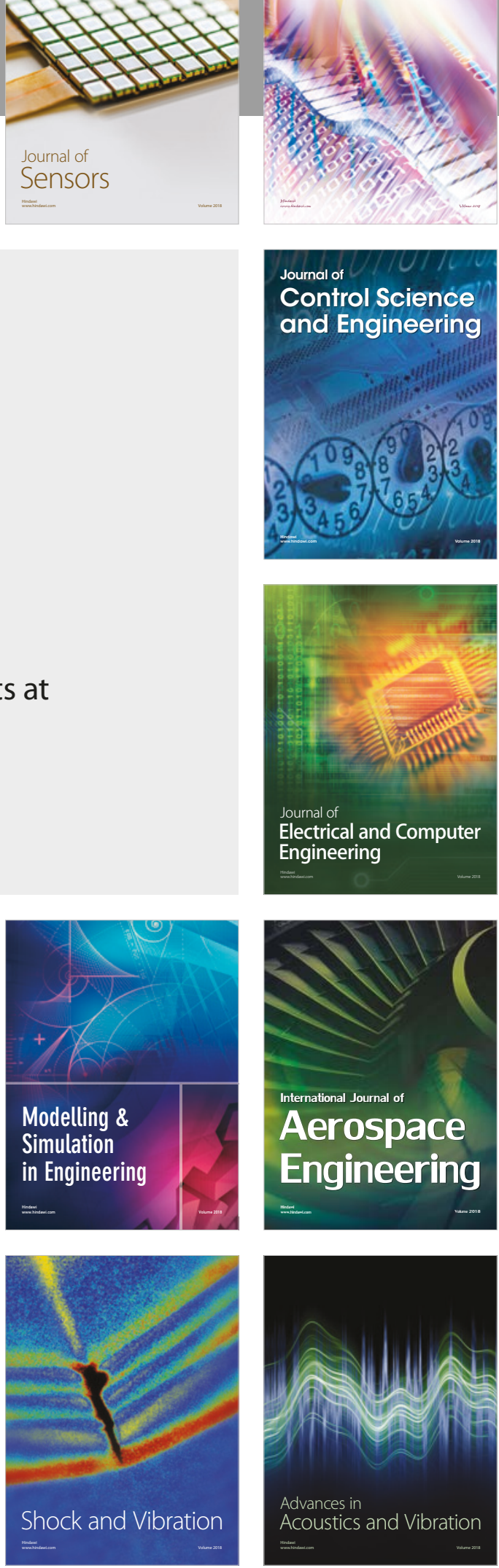